\title{
Complicações pós-operatórias em gatos hipertireoideos submetidos à tireoidectomia unilateral*
}

\author{
Unilateral thyroidectomy complications in hyperthyroid cats
}

\author{
Katia Barão Corgozinho', Heloisa Justen Moreira de Souza ${ }^{2}$, Ana Maria Ferreira ${ }^{3}$, Adriana Neves \\ Pereira ${ }^{4}$, Cristiane Brandão Damico ${ }^{4}$, Simone Carvalho dos Santos Cunha' \& Víctor do Espírito Santo \\ Cunha $^{5}$
}

RESUMO

Gatos com hipertireoidismo podem se beneficiar do tratamento cirúrgico em algumas situações, como em casos de neoplasias e intolerância a medicação. Várias técnicas já foram descritas sendo a tireoidectomia com implantação da glândula paratireóide em etapas a que mais minimiza o risco de hipocalcemia pós-cirúrgica. Este trabalho teve como objetivo avaliar as possíveis complicações pós-operatórias em gatos com hipertireoidismo submetidos à técnica de tireoidectomia unilateral com implantação da glândula paratireóide. Oito gatos com diagnóstico clínico e laboratorial de hipertireoidismo foram operados e seus níveis de cálcio ionizado avaliados com 24 e 48 horas, sete, quinze e 21 dias após a cirurgia. Resultados de exames laboratoriais (hemograma, ureia, creatinina, e tiroxina total) foram coletados sete dias após a cirurgia e comparados com os resultados obtidos no pré-operatório. Uma Análise de Variância (ANOVA One-Way) e o teste de Scheffe foram utilizados para avaliar os resultados do cálcio ionizado, enquanto que para a análise dos resultados da creatinina foi utilizado o teste t de Student $(\mathrm{p}<0,05)$. Não foram observadas alterações clínicas ou nos níveis de cálcio após a cirurgia e, apesar dos níveis de cálcio após a cirurgia terem diminuído, essa variação não foi significativa $(\mathrm{p}=0,149)$. Os níveis séricos de creatinina aumentaram significativamente $(\mathrm{p}=0,026)$. Estes resultados sugerem que a técnica descrita é segura e que pode ser curativa em determinados casos de hipertireoidismo felino sem doença renal prévia.

Descritores: tireóide, cirurgia, hipocalcemia.

\section{ABSTRACT}

Thyroid neoplasia is the primary indication for thyroidectomy in cats. Several techniques for thyroidectomy in cats have been described, but a simplified extracapsular thyroidectomy that includes transplantation of the parathyroid gland minimizes the risk of postoperative parathyroid failure resulting in life-threatening hypocalcemia. The aim of this study was to evaluate the outcomes of unilateral thyroidectomy with parathyroid gland transplantation in hyperthyroid cats. Eight cats were determined to be hyperthyroid based upon physical examination and laboratorial panel and were treating by surgery. The cats were evaluated on days 1,2, 7, 15 and 21 after the surgery, including blood draw for serum ionized calcium testing. On day 7, serum creatinine and total thyroxine testing was also performed. To test for differences between the means of pre and post treatment, ANOVA One-Way and Scheffe test were performed to evaluate ionized calcium and Student test used to evaluate serum creatinina. A $P$ value of $<0.05$ was considered to indicate statistical significance. Surgical complications were not observed. Comparison of the pre- and post-surgical ionized calcium level indicated no significant difference $(\mathrm{p}=0,149)$. However, there was a significant increase in serum creatinine concentration $(\mathrm{p}=0.026)$. Unilateral thyroidectomy with parathyroid gland transplantation was effective and safe for hyperthyroid cats with gland unilateral involvement without renal disease.

Keywords: thyroid, surgery, hypocalcemia. Filho no. 64, CEP 24230-340 Niterói, RJ, Brasil. ${ }^{2}$ Departamento de Medicina e Cirurgia, Universidade Federal Rural do Rio de Janeiro (UFRRJ), Instituto Veterinário, Seropédica, RJ, Brasil. ${ }^{3}$ Departamento de Patologia Veterinária, UFF. ${ }^{4}$ Clínica Veterinária Gatos e Gatos Vet, RJ, Brasil. ${ }^{5}$ Programa de pós-graduação em Medicina Veterinária, UFRRJ. CORRESPONDÊNCIA: K.B. Corgozinho [ katiabarao@uol.com.br - Tel + 55 (21) 3393 9514]. 


\section{INTRODUÇÃO}

O hipertireoidismo é uma doença endócrina caracterizada pelo aumento da concentração circulante de tiroxina $\left(\mathrm{T}_{4}\right)$ e triiodotironina $\left(\mathrm{T}_{3}\right)$ e é geralmente causado por hiperplasia adenomatosa de um ou ambos os lobos tireoidianos ou até mesmo do tecido tireoidiano acessório [6,14,19].

$\mathrm{O}$ tratamento do hipertireoidismo em gatos visa controlar o excesso de hormônio produzido pela glândula tireóide adenomatosa que pode ser feito através de medicamentos que diminuem a produção do hormônio, remoção cirúrgica do lobo acometido ou administração de iodo radioativo $[3,12,17,21]$.

$\mathrm{O}$ tratamento cirúrgico tem sido efetivo em gatos com hipertireoidismo e é indicado como terapia definitiva diferente da terapia clínica, sendo considerado também em casos de neoplasias [5,14]. Os animais devem ser estabilizados antes da cirurgia para diminuir os riscos anestesiológicos e cirúrgicos $[1,2$, $7,8]$.

Há várias técnicas de tireoidectomia descritas como a extracapsular e a intracapsular as quais preservam a glândula paratireóide, e a técnica mais recentemente descrita é a com implantação da glândula paratireóide na musculatura cervical $[1,7,14,15]$. A técnica cirúrgica que minimiza a hipocalcemia pósoperatória, a mais grave complicação da tireoidectomia, é a técnica de tireoidectomia com implantação da glândula paratireóide entre as fibras musculares do esternohióide [15].

O objetivo desse estudo foi avaliar as complicações após a tireoidectomia unilateral com implantação da glândula paratireóide em gatos hipertireoideos por um período de até seis meses pós-cirúrgicos.

\section{MATERIAIS E MÉTODOS}

\section{Animais}

Foram analisados os dados de oito gatos com diagnóstico clínico e laboratorial de hipertireoidismo e que foram submetidos à tireoidectomia unilateral com implantação da glândula paratireóide. Todos os gatos inclusos nesse trabalho recebiam medicação a base de metimazol e apresentavam lobos tireoidianos palpáveis no exame físico cervical. As cirurgias foram realizadas em Clínica Veterinária privada no período compreendido entre abril de 2007 e dezembro de 2008.

\section{Técnica cirúrgica}

O protocolo anestésico foi efetuado de acordo com o estado geral do paciente e doenças concomitantes. A técnica cirúrgica adotada foi a tireoidectomia extracapsular unilateral, com identificação da paratireóide externa, isolamento e implantação da mesma entre as fibras musculares do esternohióideo ipsalteral [15]. Uma sutura simples com fio inabsorvível foi realizada no local de implantação da glândula paratireóide com intuito de se evitar dano à mesma, caso fosse necessário a retirada do lobo tireoidiano contralateral futuramente.

\section{Parâmetros analisados}

- Complicações trans e pós-cirúrgicas: Os gatos foram acompanhados desde a cirurgia até seis meses pós-operatórios, sendo avaliados 24 e 48 horas, sete, quinze e 21 dias, e seis meses após cirurgia. Alterações cardíacas ou de pressão foram avaliadas durante a anestesia. A presença de hemorragia, alteração de voz, sinais de hipocalcemia e alterações de comportamento foram avaliados no pós-operatório.

- Laboratoriais: Os valores de cálcio ionizado foram obtidos no pré-cirúrgico e 24 horas, 48 horas, sete dias, 15 dias e 21 dias após a cirurgia. Hemograma, ureia e creatinina foram avaliados antes e sete dias após a cirurgia. $\mathrm{O} \mathrm{T}_{4}$ total sérico foi coletado antes e sete dias após a cirurgia e seis meses após a cirurgia naqueles casos em que os gatos se apresentaram eutireóideo no sétimo dia pós-cirúrgico.

\section{Análises estatísticas}

Uma Análise de Variância (ANOVA One-Way) e o teste de Scheffe foram utilizados para avaliar os resultados do cálcio ionizado, enquanto que para a análise dos resultados da creatinina foi utilizado o teste t de Student $(\mathrm{p}<0,05)$.

As normas descritas pelo Colégio Brasileiro de Experimentação Animal (COBEIA), lei 6.638, de 8 de Maio de 1979 para a garantia do bem estar animal foram seguidas e os procedimentos descritos neste projeto foram avaliados pela comissão de Bioética da Universidade Federal Fluminense.

\section{RESULTADOS}

\section{Animais}

Dos oito gatos incluídos neste estudo, cinco eram machos e três fêmeas e pesavam entre 2,290 a $5,320 \mathrm{~kg}(\bar{x}=3,66)$. Dois animais apresentaram lobos 
tireoidianos aumentados bilateralmente e seis com somente um lobo cervical palpável. Os motivos pelos quais os animais foram submetidos ao tratamento cirúrgico foram: efeitos adversos à medicação oral (50\%), não estabilização do quadro clínico mesmo com altas doses de medicação $(25 \%)$ e vontade do proprietário de suspender definitivamente o tratamento clínico $(25 \%)$.

\section{Técnica cirúrgica}

Houve dificuldade em localizar a glândula paratireóide e a mesma não foi implantada em três animais dos oito operados.

\section{Parâmetros analisados}

- Complicações trans e pós-cirúrgicas: Não houve nenhuma intercorrência anestesiológica ou cirúrgica durante o transoperatório. Hemorragia, síndrome de Horner, perda de voz, sinais de hipocalcemia ou qualquer alteração também não desenvolveram no período pós-operatório compreendido entre 24 horas a seis meses.

- Laboratoriais: Os valores de cálcio ionizado obtidos no pré-cirúrgico e 24 horas, 48 horas, sete dias, 15 e 21 dias após a cirurgia revelaram diminuição após a cirurgia, porém esse declínio não foi es- tatisticamente significativo $(p>0,05)$ e o valor sérico de cálcio ionizado não abaixou do limite mínimo de referência.

As enzimas renais, ureia e creatinina séricas, aumentaram significativamente sete dias após a cirurgia $(\mathrm{p}<0,05)$ quando comparadas aos valores précirúrgicos.

Um animal apresentou $\mathrm{T}_{4}$ total sérico aumentado sete dias após a cirurgia e dois animais apresentaram $\mathrm{T}_{4}$ total sérico aumentado após seis meses da cirurgia retornando ao quadro de hipertireoisdismo. Os outros cinco gatos do estudo permaneceram eutireóideos.

\section{Análises estatísticas}

A Análise de Variância (ANOVA One-Way) e o teste de Scheffe utilizados para avaliar os resultados do cálcio ionizado revelaram nenhuma diferença significativa entre os valores pré-cirúrgicos, 24 horas, 48 horas, sete, quinze e vinte um dias $\left(\mathrm{F}_{5 ; 0,05}=\right.$ 1,747; $p=0,149$ ) (Gráfico 1).

O teste t de Student avaliando o nível sérico de creatinina antes e sete dias após a cirurgia apresentou diferenças significativas $\left(t_{8: 0,05}=-2,722 ; p=\right.$ 0,026) (Gráfico 2).

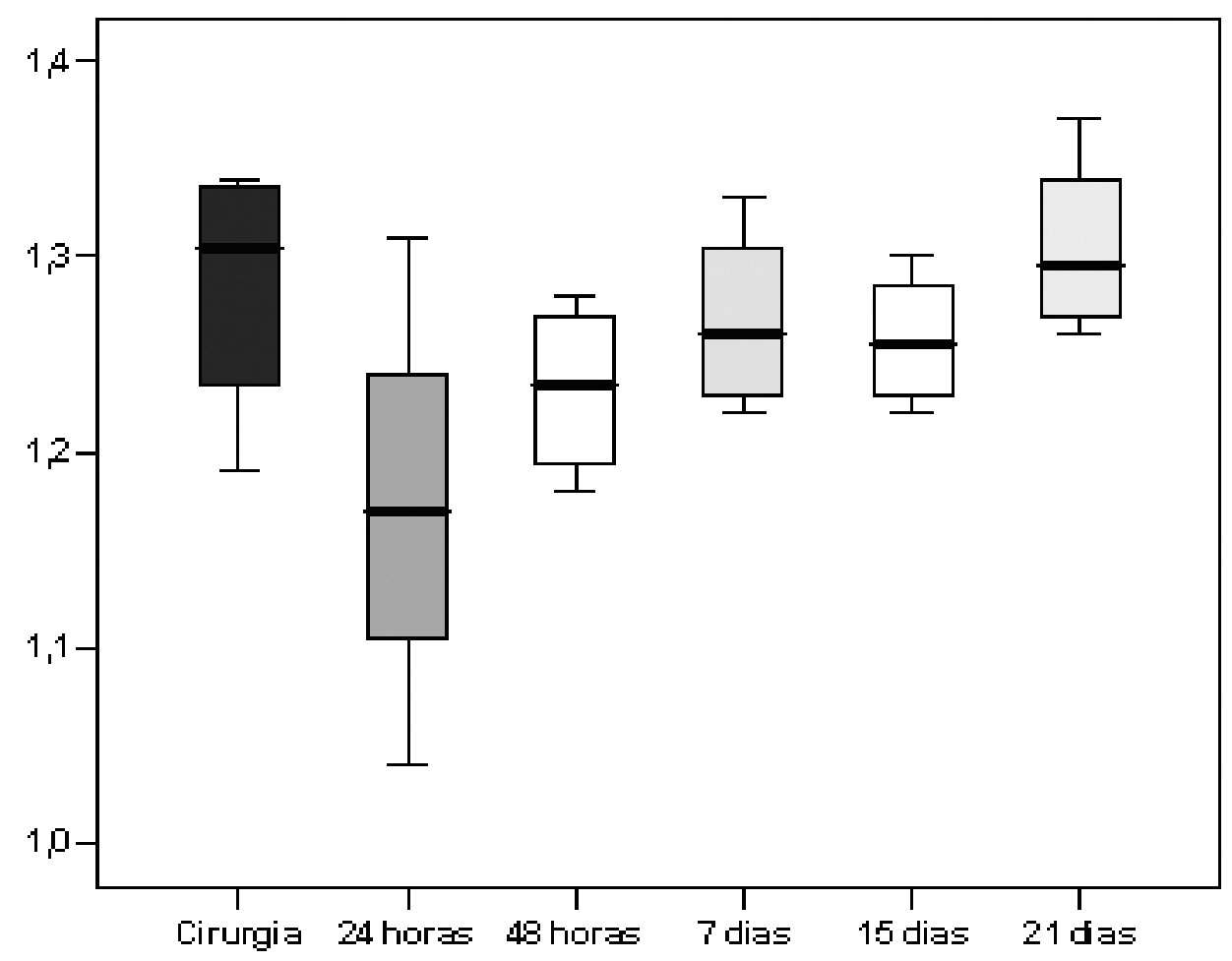

Gráfico 1. Apresenta gráfico Box-plot do nível de cálcio-ionizado dos gatos hipertireoideos submetidos a tireoidectomia unilateral antes e 24 e 48 horas, sete, quinze e 21 dias após a cirurgia. 


\section{DISCUSSÃO}

Apesar de uma maior incidência de machos acometidos $(62,5 \%)$, devido ao número pequeno de animais estudados, não é possível afirmar que existe uma predisposição em relação ao sexo. Estudos anteriores $[11,14]$ demonstraram que não há predileção por sexo e sim por raça e por idade. Em nosso estudo, os animais sem raça definida e de meia idade a idosos foram os mais acometidos.

A técnica cirúrgica empregada nesse estudo foi primeiramente descrita por Norsworthy [15]. Essa técnica cirúrgica tem como vantagem não permanecer tecido tireoidiano junto a glândula paratireóide durante a remoção do lobo tireoidiano acometido como descrito na técnica extracapsular modificada e intracapsular modificada $[1,8]$. Outra vantagem dessa técnica é o retorno da função da glândula paratireóide após a implantação no músculo esternohióideo como comprova o estudo realizado por Padgett et al. [16] que avalia histopatologicamente e funcionalmente a glândula paratireóide após a implantação nessa musculatura.

Nenhum dos gatos apresentou qualquer complicação no trans ou pós-operatório imediato provavelmente devido à estabilização pré-cirúrgica e o co- nhecimento da anatomia da região. Não foi observado espasmo laringeano, alteração de voz, hemorragia ou síndrome de Horner no pós-operatório como já relatado em outros trabalhos [14,18].

Não houve óbito durante a anestesia ou após a cirurgia como já relatado [8,14]. O animal hipertireoideo deve ser preparado com o uso de metimazol ou propanolol para ser submetido ao procedimento cirúrgico e evitar óbitos durante a cirurgia como foi o caso de animais que apresentaram complicações anestesiológicas no estudo realizado por Bichard et $a l$. [2], em função da não estabilização cardíaca previamente à cirurgia.

Apesar de ocorrer uma diminuição nos níveis de cálcio após a cirurgia, essa variação não foi significativa $(\mathrm{p}=0,149)$. A hipocalcemia pós-operatória é mais frequente quando se realiza tireoidectomia bilateral, porém se o suprimento sanguíneo da glândula paratireóide externa não for lesado, o risco de hipocalcemia é reduzido. A hipocalcemia transitória pode ocorrer em caso de edema da glândula paratireóide pela manipulação durante a cirurgia [14]. Nenhum dos nossos animais apresentou hipocalcemia assim como outros estudos que também realizaram a tireoidectomia unilateral $[4,15]$ porque as

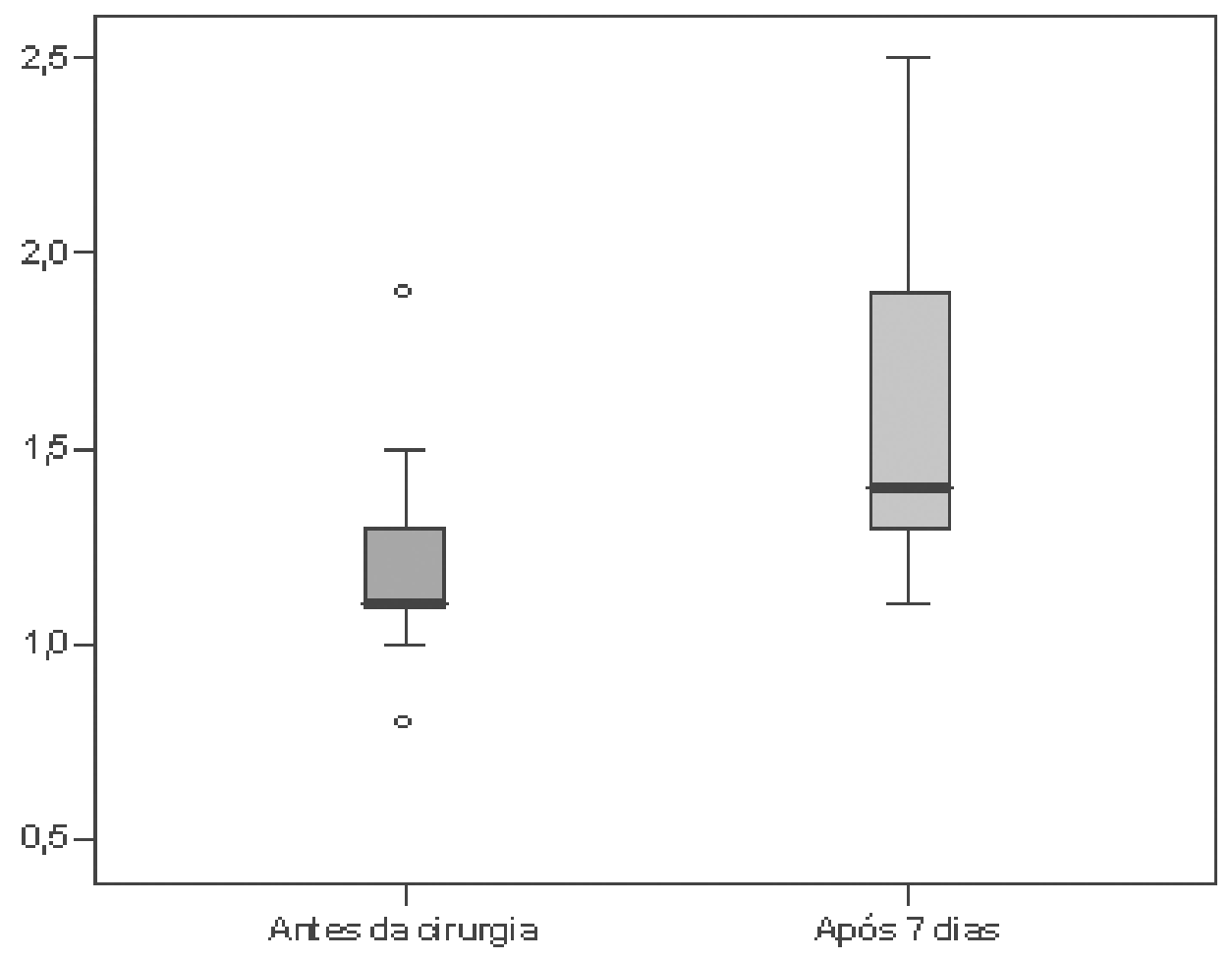

Gráfico 2. Apresenta gráfico Box-plot do nível de creatina antes e sete dias após a cirurgia dos gatos hipertireoideos submetidos a tireoidectomia unilateral. 
glândulas paratireóides externa e interna do lado contralateral mantém a normocalcemia. A presença de somente uma glândula paratireóide pode manter os níveis séricos de cálcio normais [2,9,15]. Em dez animais submetidos a paratireoidectomia com implantação da glândula paratireóide em etapas [15], ou seja, com pelo menos um mês de diferença entre as cirurgias, não houve o desenvolvimento de hipocalcemia clínica após a segunda cirurgia, provavelmente pela neovascularação da glândula paratireóide implantada na primeira cirurgia que ocorre em torno de duas semanas [16]. A grande dificuldade encontrada em nosso trabalho foi identificar a glândula paratireóide externa e em apenas cinco animais a glândula paratireóide foi implantada com sucesso. Uma complicação que pode ocorrer é a hipocalcemia após a remoção do lobo tireoidiano remanescente, nos casos onde a glândula paratireóide não foi implantada, requerendo suplementação de cálcio nesses animais até que a segunda glândula paratireóide implantada restaure a sua função.

A função renal deve ser monitorada principalmente nos gatos que demonstram evidência de disfunção renal no pré-operatório [1,13]. O hipertireoidismo aumenta a taxa de filtração glomerular e quando é corrigido pode elevar a creatinina e a ureia no soro pela diminuição da taxa de filtração glomerular [10]. Observou-se o aumento dos níveis séricos de creatinina em sete animais e em um desses o aumento excedeu o limite normal em decorrência do maior controle do nível do hormônio tireoidiano. Os valores da creatinina antes e após a cirurgia apresentaram diferenças significativas $(\mathrm{p}=0,026)$ justificando a avaliação cuidadosa da indicação de animais hipertireoideos azotêmicos para o tratamento cirúrgico do hipertireoidismo.

O hipertireoidismo é na maioria dos casos causados por alterações hiperplásicas ou adenomatosas dos dois lobos tireoidianos. O acometimento foi unilateral em 32 gatos e bilateral em 53 gatos de 85 casos descritos por Bichard et al. [2], e unilateral em nove animais e bilateral em 86 casos descritos por Naan et al. [14]. No nosso estudo somente dois apresentaram acometimento bilateral na palpação cervical. Estes achados podem ser devido a ausência da cintilografia na Medicina Veterinária Brasileira, método de diagnóstico mais fidedigno do que a pal- pação cervical. A realização da tireoidectomia unilateral nos animais que tem envolvimento unilateral pode ser curativa [2] como foi observado nos gatos relatados nesse estudo acompanhados por um período de seis meses. Porém esses animais devem ser acompanhados para possível retorno do hipertireoidismo já que permaneceram com um lobo tireoidiano.

Houve recorrência do hipertireoidismo em três gatos. Isso se deve a hiperplasia do outro lobo tireoidiano remanescente. A retirada desse lobo provavelmente levaria a remissão completa do quadro de hipertireoidismo. Após a cirurgia, o retorno ao quadro clínico de hipertireoidismo ocorre em função da presença do outro lobo tireoidiano funcional, da remanescência de tecido tireoidiano ou da presença de tecido tireoidiano ectópico [14,20]. Por isso, o uso da cintilografia se faz necessário, para a detecção de tecido tireoidiano ectópico ou remanescente antes da cirurgia $[2,11,12,14$,$] . Dos três animais que volta-$ ram a apresentar hipertireoidismo, um deles não apresentava sinais clínicos e estava mais pesado que antes da cirurgia, assim como ocorreu em um relato onde um animal apresentava hormônio tireoidiano aumentado, mas não apresentava sinal clínico [22]. No trabalho realizado por Flanders et al. [8], cinco de nove gatos apresentando hiperatividade de ambos os lobos na cintilografia foram submetidos a tireoidectomia unilateral e após um mês de cirurgia permaneciam eutireoideos. O ideal é o acompanhamento desses animais pelos próximos dois anos, pois o retorno pode acontecer em torno de um ano após a tireoidectomia unilateral [15].

\section{CONCLUSÃO}

A cirurgia é um tratamento simples e eficaz para animais que tenham hipertireoidismo e lobo tireoidiano cervical palpável. A implantação da glândula paratireóide externa permite a remoção de todo tecido tireoidiano acometido, o que diferencia esta técnica das outras técnicas cirúrgicas já descritas. A tireoidectomia unilateral não leva a hipocalcemia póscirúrgica e pode ser considerada como tratamento definitivo para animais que apresentam acometimento unilateral. Quando os dois lobos estão acometidos, a tireoidectomia bilateral em etapas é indicada. Seguindo a técnica de tireoidectomia corretamente, não se observam complicações pós-operatórias. 


\section{REFERÊNCIAS}

1 Bichard S.J. 2006. Thyroidectomy in the cat. Clinical Techniques in Small Animal Practice. 21(1): 29-33.

2 Bichard S.J., Peterson M.E. \& Jacobson A. 1984. Surgical treatment of feline hyperthyroidism: results of 85 cases. Journal of the American Animal Hospital Association. 20: 705-709.

3 Carlos R.S.A. \& Albuquerque G.R. 2005. Hipertireoidismo felino - relato de caso. Clínica Veterinária. 57: 56-60.

4 Corgozinho K.B., Cunha S.C.S, Souza H.J.M., Pinheiro I.M. \& Ferreira A.M.R. 2008. Dosagem de cálcio ionizado em gatos submetidos a tireoidectomia. Ciência Animal Brasileira. (supl. 1): 281-283.

5 Corgozinho K.B., Souza H.J.M., Ferreira A.M.R., PereiraA.N. \& Cunha S.C.S., Moura M.P. 2007. Tireoidectomia com reimplantação da paratireóide em um gato. Acta Scientiae Veterinariae. 35(Supl 2): 352-353.

6 Feldman E.C. \& Nelson R.W. 1999. Feline hyperthyroidism. In: Feldman E.C. \& Nelson R.W. (Eds). Canine and feline endocrinology and reproduction. 3rd edn. Saint Louis: Saunders, pp.152-218.

7 Flanders J.A. 1999. Surgical options for the treatment of hyperthyroidism in the cat. Journal of Feline Medicine and Surgery. 1(3): 127-134.

8 Flanders J.A., Harvey H.J. \& Erb H.N. 1987. Feline thyroidectomy: a comparison of postoperative hypocalcemia associated with three different surgical techniques. Veterinary Surgery. 16(5): 362-366.

9 Flanders J.A. Neth S., Erb H. N. \& Kallfelz F.A. 1991. Fuctional analysis of ectopic parathyroid activity in cats. American Journal of Veterinary Research. 52(8): 1336-1340.

10 Graves T.K., Olivier B., Nachreiner R.F., Kruger J.M., Walshaw R. \& Stickle R.L. 1994. Changes in renal function associated with treatment of hyperthyroidism in cats. American Journal of Veterinary Research. 55(12): 1745-1749.

11 Harvey A.M., HibbertA., Barrett E.L., Day M.J., Quiggin A.N., Brannan R.M. \& Caney S.M.A. 2009. Scintigraphic findings in 120 hyperthyroid cats. Journal of Feline Medicine and Surgery. 11(2): 96-106.

12 Hibbert A., Gruffydd-Jones T., Day M.J. \& Harvey A.M. 2009. Feline thyroid carcinoma: diagnosis and response to highdose radioactive iodine treatment. Journal of Feline Medicine and Surgery. 11(2): 116-124.

13 Langston, C.E. \& Reine N.J. 2006. Hyperthyroidism and the kidney. Clinical Techniques in Small Animal Practice. 21(1): 17-21.

14 Naan E.C., Kirpensteijn J., Kooistra H.S. \& Peters M.E. 2006. Results of thyroidectomy in 101 cats with hyperthyroidism. Veterinary Surgery. 35(3): 287-293.

15 Norsworthy G.D. 1995. Feline thyroidectomy: a simplified technique that preserves parathyroid function. Veterinary Medicine. 90(11): 1055-1063.

16 Padgett S.L., Tobias K.M., Leathers C.W. \& Wardrop K.J. 1998. Efficacy of parathyroid gland autotransplantation in maintaining serum calcium concentrations after bilateral thyroparathyroidectomy in cats. Journal of the American Hospital Association. 34(3): 219-224.

17 Peterson M.E. 2006. Radioiodine treatment of hyperthyroidism. Clinical Techniques in Small Animal Practice. 21(1): 34-39.

18 Radlinsky M.A.G. 2007. Thyroid surgery in dogs and cats. Veterinary Clinics of North America: Small Animal Practice. 37(4): 789-798.

19 Shiel R.E. \& Mooney C.T. 2007. Testing for hyperthyroidism in cats. Veterinary Clinics of North America: Small Animal Practice. 37(4): 671-691.

20 Swalec K.M. \& Bichard S.J. 1990. Recurrence of hyperthyroidism after thyroidectomy in cats. Journal of the American Animal Hospital Association. 26: 433-437.

21 Trepanier L.A. 2006. Medical management of hyperthyroidism. Clinical Techniques in Small Animal Practice. 21(1): 22-28.

22 Welches C.D., Scavelli T.D., Matthiesen D.T. \& Peterson M.E. 1989. Occurrence of problems after three techniques of bilateral thyroidectomy in cats. Veterinary Surgery. 18(5): 392-396.

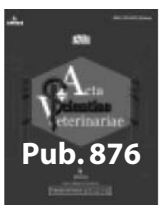

